\title{
A facile route for hydroxyapatite densification with an increased heating rate
}

\author{
Miodrag J. Lukić ${ }^{\mathrm{a}, *}$, Meltem Sezen $^{\mathrm{b}}$, Đorđe Veljovićc ${ }^{\mathrm{c}}$, Ana Mrakovićc ${ }^{\mathrm{d}}$ \\ ${ }^{a}$ Institute of Technical Sciences of the Serbian Academy of Sciences and Arts, Belgrade, Serbia \\ ${ }^{\mathrm{b}}$ Sabanci University Nanotechnology Research and Application Center (SUNUM), Istanbul, Turkey \\ ${ }^{\mathrm{c}}$ Faculty of Technology and Metallurgy, University of Belgrade, Belgrade, Serbia \\ ${ }^{\mathrm{d}}$ Laboratory of Theoretical and Condensed Matter Physics, "Vinča" Institute of Nuclear Sciences, University of Belgrade, Belgrade, Serbia
}

\section{A R T I C L E I N F O}

\section{Article history:}

Received 23 January 2017

Received in revised form 14 June 2017

Accepted 2 July 2017

Available online 8 July 2017

\begin{abstract}
A B S T R A C T
The densification behavior of hydroxyapatite nanorods prepared by chemical precipitation method in open reactor conditions was investigated by application of different heating rates. The non-isothermal processing was performed with 2,10 , and $50^{\circ} \mathrm{C} / \mathrm{min}$ up to $1200^{\circ} \mathrm{C}$ and yielded fully dense ceramics. The implementation of the higher heating rate provided grain size refinement from micrometer level for the slowest ramp, down to $250 \mathrm{~nm}$ in the case of processing with $50{ }^{\circ} \mathrm{C} / \mathrm{min}$, without any drawbacks regarding final density. The relative amount of retained structural hydroxyl groups in sintered ceramics was gradually increased with the heating rate. Furthermore, the qualitative level of optical translucency was increased with a higher heating rate which can be explained by the beneficial alignment of HAp nanorods during the fast heating rate processing, achieved microstructural refinement, and higher amount of structural hydroxyl groups.
\end{abstract}

(c) 2017 Elsevier B.V. All rights reserved.

\section{Introduction}

Conventional sintering of HAp was usually referred from the standpoint of the sintering temperature, while less attention was given to the heating rate, especially in the case of conventional pressureless sintering. However, with progress in synthesis procedures [1], any processing parameter that changes materials properties becomes critical. Sintering temperatures for conventional sintering of HAp are usually in the range from 850 to $1200{ }^{\circ} \mathrm{C}$, while holding times can vary from 1 to even $20 \mathrm{~h}$, depending on the sintering temperature and regime used [2-4]. Heating rate influences the thermal history during sintering process and forms the initial microstructure before foreseen isothermal sintering step. This can be an even stronger for materials that undergo structural chemical changes during sintering, which is the case for HAp ceramics that could lose structural carbonate and/or hydroxyl groups. Moreover, during sintering of non-stoichiometric HAp ceramics, change in phase composition might happen which additionally influences the microstructural evolution [2-4].

This study addresses non-isothermal densification behavior of HAp nanorods with heating rates from 2 to $50^{\circ} \mathrm{C} / \mathrm{min}$ up to $1200^{\circ} \mathrm{C}$, as well as corresponding microstructural and phase characterizations. It is showed that fully densified ceramics can be

\footnotetext{
* Corresponding author.

E-mail address: miodrag.lukic@itn.sanu.ac.rs (M.J. Lukić).
}

obtained in significantly reduced time frame. The obtained results are important for further improving the both HAp synthesis and sintering pathways.

\section{Materials and methods}

HAp nanorods are synthesized by the chemical precipitation method in open reactor conditions, at ambient pressure. The initial ratio of $\mathrm{Ca} / \mathrm{P}$ was set to stoichiometric 1.67 for $\mathrm{HAp} . \mathrm{Ca}\left(\mathrm{NO}_{3}\right)_{2} \cdot 4 \mathrm{H}_{2} \mathrm{O}$ and $\mathrm{NH}_{4} \mathrm{H}_{2} \mathrm{PO}_{4}$ were separately dissolved in distilled water, accompanied with the addition of $\mathrm{NH}_{4} \mathrm{OH}$ to adjust $\mathrm{pH}$ value to 11 . The solution of phosphates was dropwise added to calcium solution. The reactor temperature was $50{ }^{\circ} \mathrm{C}$ during the reaction time of $1.5 \mathrm{~h}$. After $24 \mathrm{~h}$ in a native solution, the slurry was washed out to the neutral $\mathrm{pH}$. Drying was performed for $18 \mathrm{~h}$ at $100^{\circ} \mathrm{C}$. XRD measurements (Rigaku Smartlab SAXS diffractometer, Japan) with the step of 0.05 , and dwell time of $1.0 \mathrm{deg} / \mathrm{min}$. Reflections of HAp are assigned referencing to ICSD card number \# 99358. Particle size distribution (PSD) measurements (Malvern, UK) were performed from water dispersion of HAp powder. Scanning electron microscopy (SEM) imaging of HAp powder was done on Pt/Pdcoated samples (JEOL, Japan), while fractured surfaces of sintered samples were imaged on field-emission SEM (TESCAN, Czech Republic). Fourier transform infrared (FTIR) spectra of the samples were recorded at ambient conditions (Nicolet IS 50, USA), operating in the ATR mode and resolution of $4 \mathrm{~cm}^{-1}$ with 32 scans. The 
green samples were prepared by uniaxial pressing at $200 \mathrm{MPa}$, in $8 \mathrm{~mm} \emptyset$ mold. Non-isothermal sintering was performed in a vertical dilatometer system (Setsys Evolution, Setaram, France) with heating/cooling rates of 2,10 , and $50^{\circ} \mathrm{C} / \mathrm{min}$ up to $1200^{\circ} \mathrm{C}$ with no holding time at that temperature. Sintering curves were calculated from the recorded change in sample's height, assuming isotropic shrinkage [5], which was experimentally confirmed by geometrical measurements after sintering.

\section{Results and discussion}

XRD pattern of synthesized material, Fig. 1a, shows the presence of reflections that correspond to the single phase HAp. The crystallite size in $\left[\begin{array}{lll}0 & 0 & 2\end{array}\right]$ crystallographic direction is estimated to $36 \mathrm{~nm}$ according to Scherrer's equation. FTIR spectrum, Fig. 1b, reveals the bands originating from phosphate and hydroxyl groups vibrations, as well as traces of incorporated carbonates into the crystal lattice of HAp. Phosphate vibration modes exist at: $v 1$ at $962 \mathrm{~cm}^{-1}, v 2$ at $473 \mathrm{~cm}^{-1}, v 3$ at 1024 and $1092 \mathrm{~cm}^{-1}$, and $v 4$ at 560 and $602 \mathrm{~cm}^{-1}$. The peaks from hydroxyl group are present at 630 and $3569 \mathrm{~cm}^{-1}$ [6]. Vibration bands of carbonates at 874 and $1419 \mathrm{~cm}^{-1}$ originate from incorporated species at the position of a phosphate group (B-type substitution), while the peak at $1455 \mathrm{~cm}^{-1}$ can be ascribed to carbonates at the position of a hydroxyl group (A-type substitution). The positions of peaks corresponding to structural carbonate ions imply that the prepared material can be regarded as B-type carbonated HAp, although some amount of carbonates at the place of the hydroxyl group cannot be excluded. The peaks at $1640 \mathrm{~cm}^{-1}$ and between 3100 and
$3400 \mathrm{~cm}^{-1}$ indicate the presence of retained surface water. There are no any traces of residual nitrates or ammonium ions which can affect thermal and sintering behavior. Fig. 1c shows the particle size and the morphology of powder which consists of welldispersed particles with a length of $300 \mathrm{~nm}$ and width of $30 \mathrm{~nm}$. This finding is in a good agreement with the results of PSD, Fig. $4 \mathrm{~d}$, where the number particle size distribution indicates a peak around $350 \mathrm{~nm}$. However, the presence of agglomerates of several micrometers in size is seen in volume PSD, which is a typical feature of nanopowders synthesized without the presence of agents that prevent agglomeration.

Non-isothermal sintering curves of HAp nanopowder are shown in Fig. 2a. As can be seen, the choice of heating rate influences the position of sintering curves, shifting them towards higher temperatures with the heating rate. While there is no significant difference between 2 and $10^{\circ} \mathrm{C} / \mathrm{min}$, processing of HAp with a heating rate $50{ }^{\circ} \mathrm{C} / \mathrm{min}$ shifts the intermediate sintering stage for almost 150 degrees, although sample achieves the similar final density at $1200^{\circ} \mathrm{C}$. After sintering, all samples have relative density $>98 \%$ of theoretical density of HAp, based on geometrical measurements, which is usually considered as a fully dense material (>96\%). XRD patterns of sintered samples presented in Fig. $2 \mathrm{~b}$ show that the only present phase is pure HAp regardless the heating rate, which confirms the thermal stability of the material. Investigation of microstructural properties of non-isothermally sintered ceramics, Fig. 3, reveals that all samples possess practically fully dense microstructure. The average grain size is decreasing for the samples processed with faster heating: from micrometer-level in the case of $2{ }^{\circ} \mathrm{C} / \mathrm{min}, 500 \mathrm{~nm}$ for $10^{\circ} \mathrm{C} / \mathrm{min}$, and finally around $250 \mathrm{~nm}$ for the fastest heating rate of $50^{\circ} \mathrm{C} / \mathrm{min}$. In the inset of
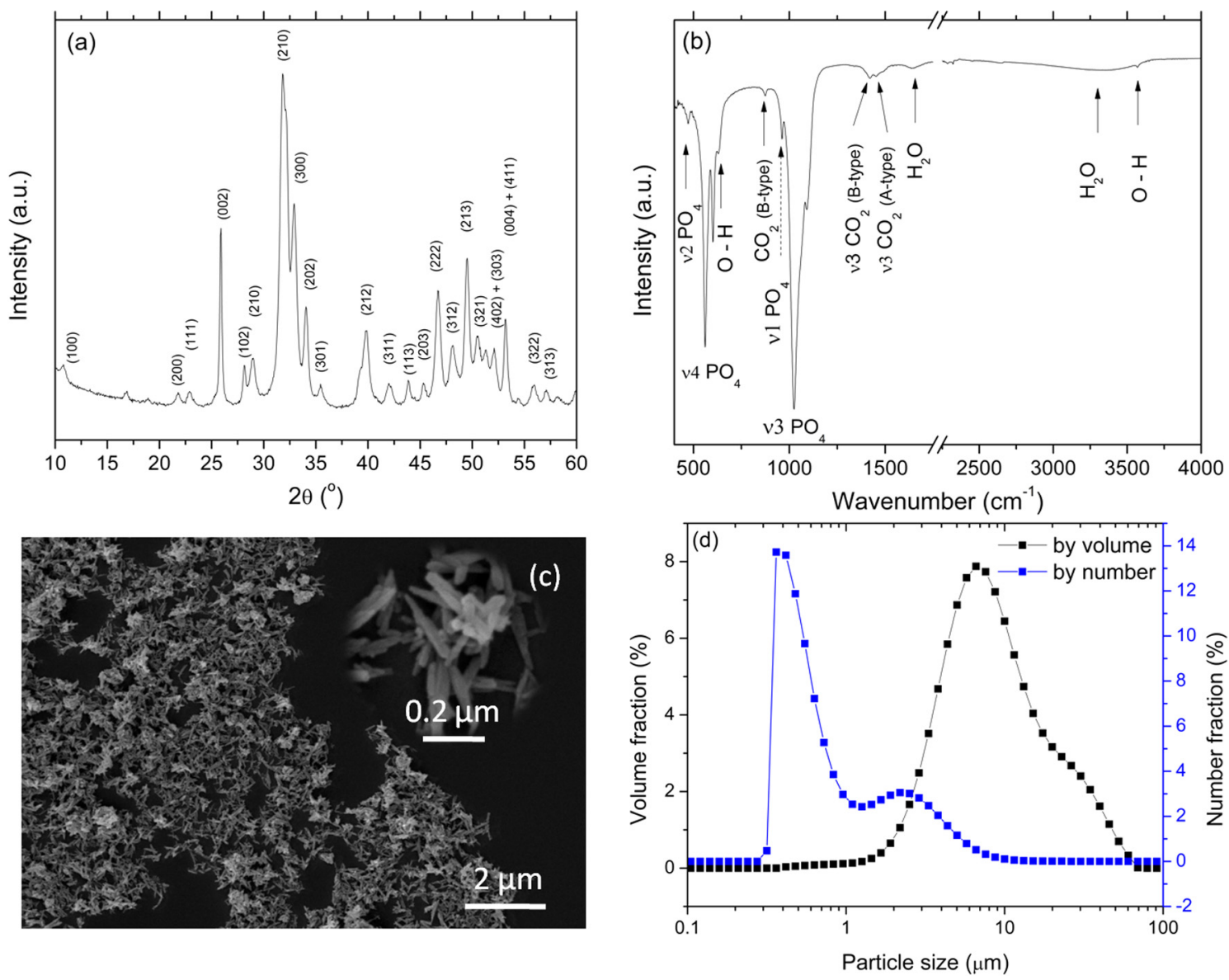

Fig. 1. Physicochemical characterization of prepared HAp: (a) XRD pattern, (b) FTIR spectrum, (c) FE-SEM image, and (d) PSDs. 

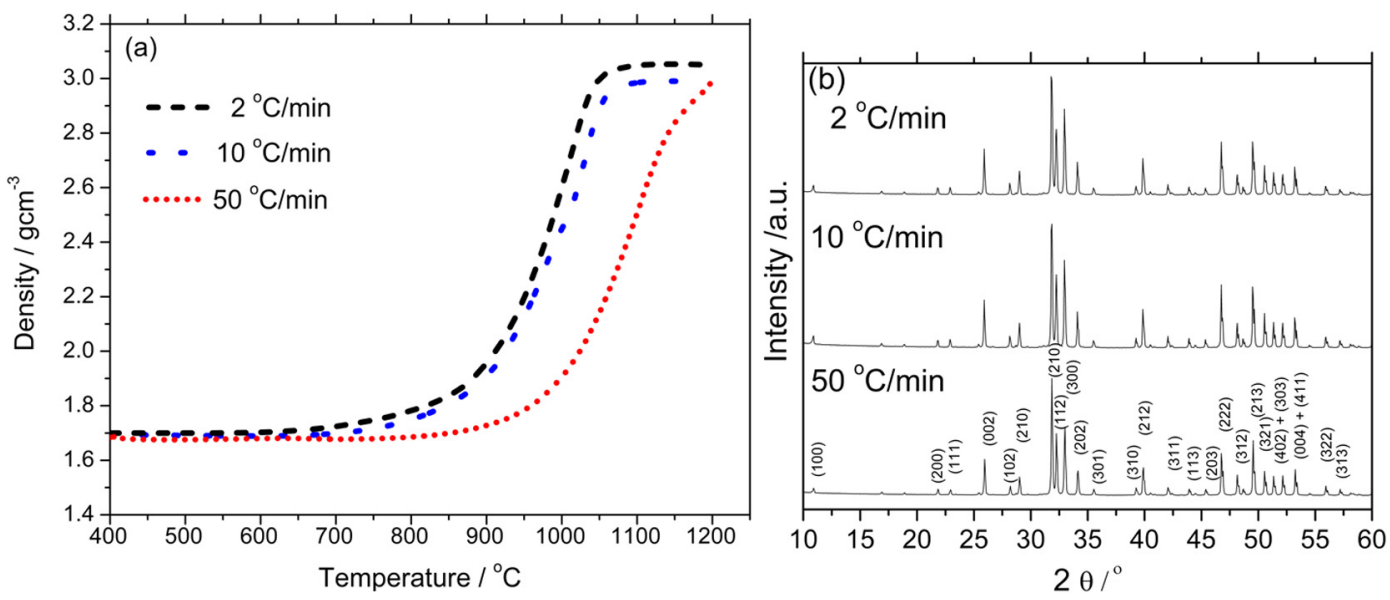

Fig. 2. (a) Non-isothermal sintering curves with different heating rates and (b) XRD patterns after sintering.

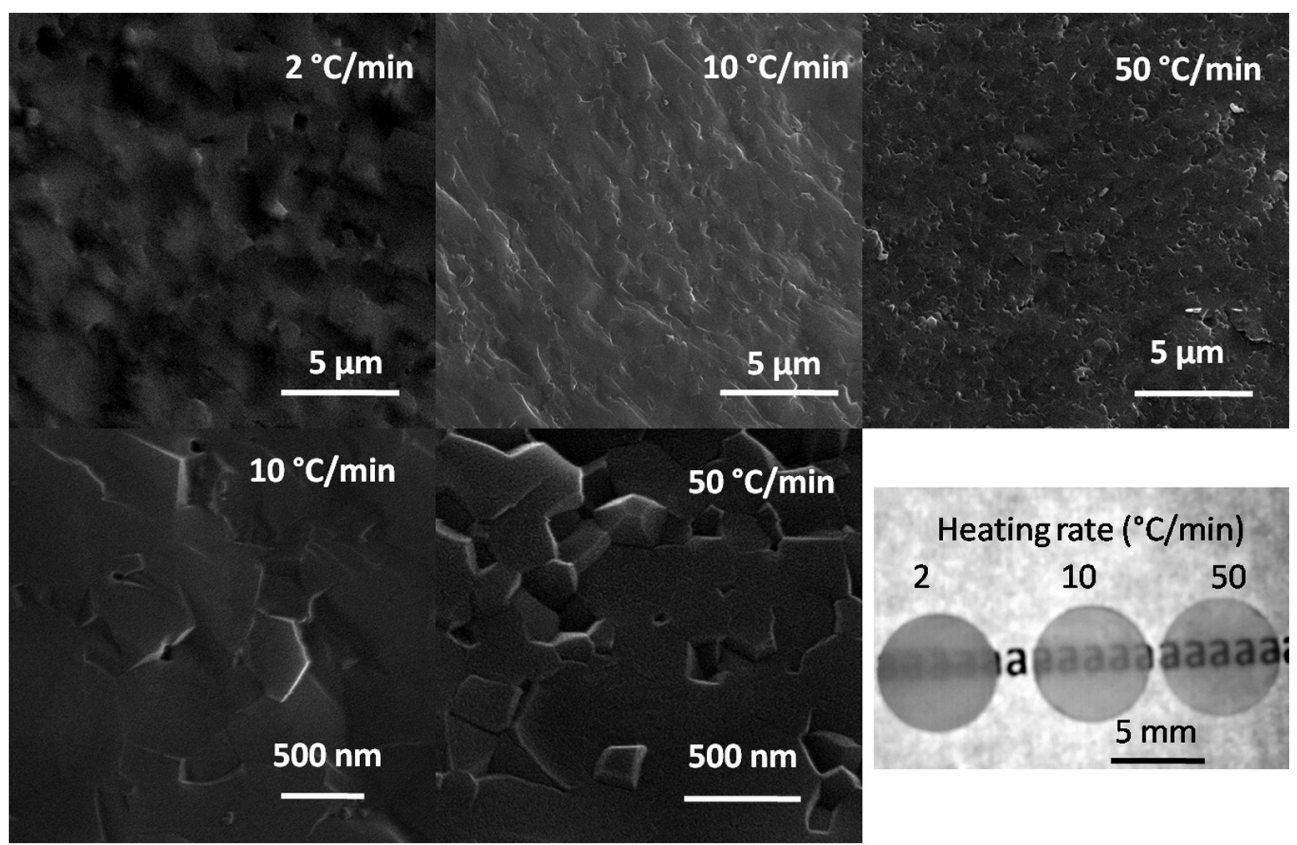

Fig. 3. SEM-SE (secondary electron) images of fractured surfaces of sintered ceramics; an inset shows the apparent translucency of 1 mm thick samples.

Fig. 3, a qualitative evidence of different optical translucency of sintered HAp specimens prepared with different heating rates is given. Such behavior was also observed for $\mathrm{ZnS}$, however, the beneficial effect was found for the slowest heating rate of $5^{\circ} \mathrm{C} / \mathrm{min}$ [7].

FTIR spectra of sintered samples, Fig.4a, exhibit the presence of characteristic phosphate vibration modes, as well as that of a hydroxyl group. The bands from incorporated carbonates are almost diminished, especially the band at $874 \mathrm{~cm}^{-1}$, while traces around $1456 \mathrm{~cm}^{-1}$ can be discussed. This finding is in accordance with a recent study on sintered HAp-based ceramics [6]. The increase in the heating rate, and thus less time spent at higher temperatures, influences the relative amount of structural hydroxyl group, Fig.4b, where the intensity of hydroxyl vibration at $630 \mathrm{~cm}^{-1}$ is getting stronger with the increase in heating rate, implying lower structural dehydroxylation.

The presented results show that the choice of the appropriate heating rate is a very important step in sintering of HAp ceramics and that interplay of heating rate and sintering temperature has to be carefully chosen to synthesize materials with desired microstructural properties. Moreover, this is the first time that fully dense HAp is obtained by a single conventional heating step in less than $25 \mathrm{~min}$, having an increased level of optical translucency. These findings could be explained by the beneficial alignment of HAp nanorods during the fast heating rate processing, achieved microstructural refinement, and higher amount of structural hydroxyl groups due to the significantly less time spent at high temperatures.

\section{Conclusion}

Variation of the heating rate during processing of HAp ceramics was successfully applied to densify HAp powdered material. The application of faster heating did not influence the final density of ceramics and contributed to the grain size refinement. The 

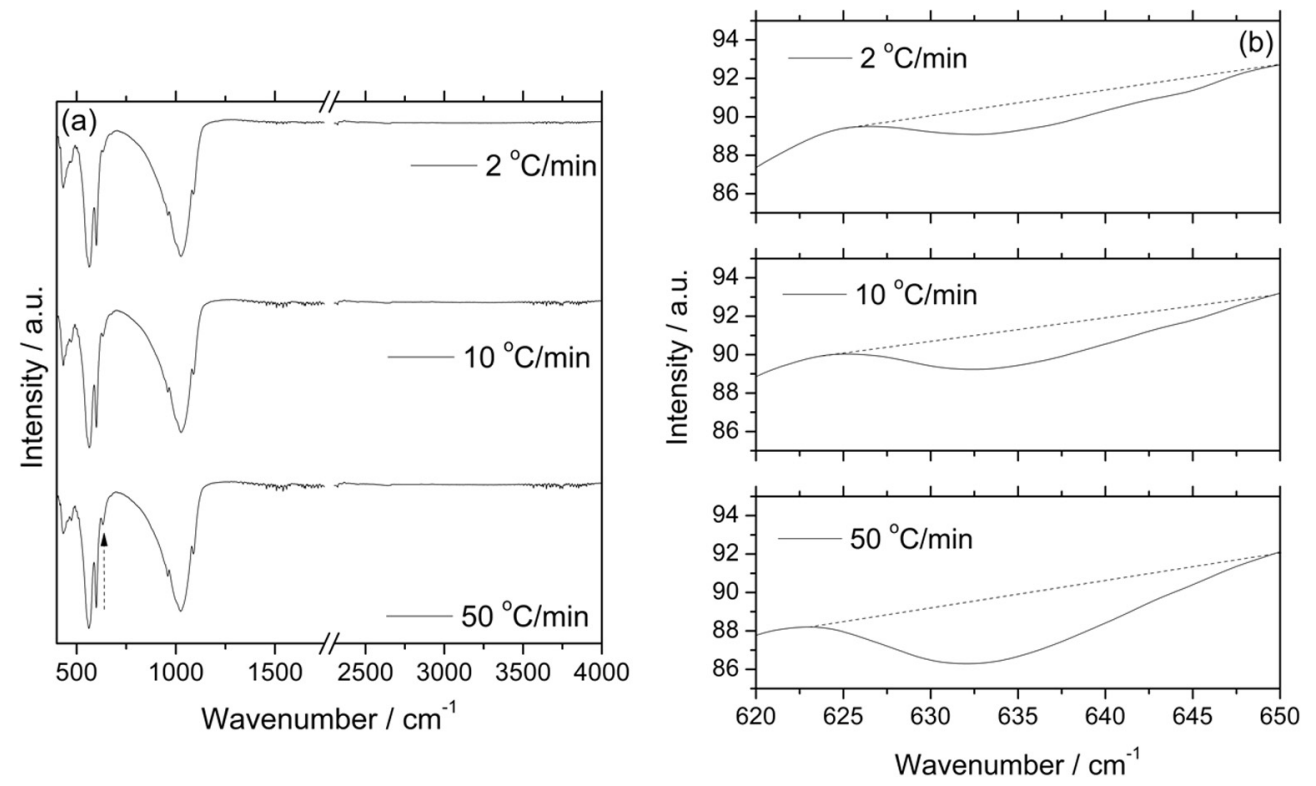

Fig. 4. (a) FTIR spectra after non-isothermal sintering and (b) the part of FTIR spectra in the range from 620 to $650 \mathrm{~cm}^{-1}$ showing the structural $\mathrm{O}-\mathrm{H}$ vibration band.

retention of a higher amount of structural hydroxyl groups was detected with the heating rate increase, as well as the optical translucency of sintered specimens. The obtained findings are useful standpoint for further research in sintering of HAp ceramics by application of an optimized heating rate. It is foreseen that such approach accompanied with the techniques suitable for microstructural optimization, like two-step sintering, can introduce an additional advantage since the driving force for densification would be preserved to a larger extent.

\section{Acknowledgements}

The authors acknowledge funding from the Ministry of Education, Science and Technological Development of the Republic of Serbia under grant III 45004. M.J.L. conceived the study, performed HAp synthesis, PSD determination, sintering experiments, and wrote the paper; M.S. measured morphological properties of powder; Đ.V. imaged microstructure of sintered specimens; A.M. performed XRD and FTIR measurements. All authors contributed to paper writing and approved the manuscript. The authors declare no competing conflict of interests.

\section{References}

[1] M.-T.K. Mehdi Sadat-Shojai, Synthesis methods for nanosized hydroxyapatite with diverse structures, Acta Biomater. 9 (2013) 7591-7621, http://dx.doi.org/ 10.1016/j.actbio.2013.04.012.

[2] M.J. Lukić, L. Veselinović, Z. Stojanović, M. Maček-Kržmanc, I. Bračko, S.D. Škapin, S. Marković, D. Uskoković, Peculiarities in sintering behavior of Cadeficient hydroxyapatite nanopowders, Mater. Lett. 68 (2012) 331-335, http:// dx.doi.org/10.1016/j.matlet.2011.10.085.

[3] M.J. Lukić, S.D. Škapin, S. Marković, D. Uskoković, Processing route to fully dense nanostructured hap bioceramics: from powder synthesis to sintering, J. Am. Ceram. Soc. 95 (2012) 3394-3402, http://dx.doi.org/10.1111/j.15512916.2012.05376.x.

[4] E. Champion, Sintering of calcium phosphate bioceramics, Acta Biomater. 9 (2013) 5855-5875, http://dx.doi.org/10.1016/j.actbio.2012.11.029.

[5] A.R. Boccaccini, P.A. Trusty, In situ characterization of the shrinkage behavior of ceramic powder compacts during sintering by using heating microscopy, Mater. Charact. 41 (1998) 109-121, http://dx.doi.org/10.1016/S1044-5803(98)000254.

[6] C. João, R. Almeida, J. Silva, J. Borges, A simple sol-gel route to the construction of hydroxyapatite inverted colloidal crystals for bone tissue engineering, Mater. Lett. 185 (2016) 407-410, http://dx.doi.org/10.1016/j.matlet.2016.09.030.

[7] Y. Chen, L. Zhang, J. Zhang, P. Liu, T. Zhou, H. Zhang, D. Gong, D. Tang, D. Shen, Fabrication of transparent $\mathrm{ZnS}$ ceramic by optimizing the heating rate in spark plasma sintering process, Opt. Mater. 50 (2015) 36-39, http://dx.doi.org/ 10.1016/j.optmat.2015.03.058. 